\title{
Vibrational Spectrum of the Unordered Polypeptide Chain: A Raman Study of Feather Keratin
}

\author{
S. L. HSU, W. H. MOORE, and S. KRIMM, Harrison M. Randall \\ Laboratory of Physics and Macromolecular Research Center, \\ University of Michigan, Ann Arbor, Michigan 48104
}

\begin{abstract}
Synopsis
Raman spectra of native and solubilized feather keratin have been obtained, and the amide I and amide III regions have been analyzed by band resolution techniques. The amide I region of the native form indicates that at least $64 \%$ of the protein has an antiparallel chain pleated sheet structure, the remainder being unordered. For the solubilized keratin all of the protein is in an unordered state. The amide III region is not as easily analyzed into component contributions. Normal vibration analyses on $N$-acetyl-L-alanine- $N$-methylamide support the conclusion that the amide III region is not as satisfactory as the amide I region in characterizing unordered structures. Even in the latter case caution must be used, since the observed amide I band is an average over the conformational distribution in the particular unordered system.
\end{abstract}

\section{INTRODUCTION}

The vibrational spectra of ordered polypeptide chain structures have been the subject of extensive experimental study, from which empirical correlations of spectrum with structure have emerged. ${ }^{1}$ These correlations have received strong support from theoretical studies, which have incorporated normal vibration analyses as well as perturbation effects in helping to explain the details of the vibrational spectra. ${ }^{2}$ Recent developments in elucidating the physical origins of the perturbation contributions ${ }^{3,4}$ and in refining the potential functions for normal vibration analysis ${ }^{5}$ have placed the interpretation of the vibrational spectra of regular polypeptide structures on a secure basis.

The situation is not nearly as satisfactory with respect to the interpretation of the spectra of unordered polypeptide chains. In early studies, for example, the amide I mode of such structures had been identified with the "unperturbed" $\left(\nu_{0}\right)$ frequency of the peptide group, which was predicted ${ }^{6,7}$ at $1656-1658 \mathrm{~cm}^{-1}$. This value seemed to be in accord with that observed in the infrared spectrum for the unordered component of silk fibroin. ${ }^{8}$ More recent work, showing that perturbations of the amide I frequency arise from transition dipole coupling effects, 3,4 leads to the prediction that $\nu_{0} \cong 1680 \mathrm{~cm}^{-1}$, thus invalidating the above assignment (although not necessarily the observed correlation). 
Raman spectroscopic studies of synthetic and natural polypeptides have also been used to identify unordered structures: ${ }^{9-22}$ the amide $I$ band has been assigned in the range of $1649-1667 \mathrm{~cm}^{-1}$ (with some assignments as high as $1685 \mathrm{~cm}^{-1}$ for "unsolvated" groups ${ }^{15}$ ), and the amide III band has been assigned in the range of $1239-1262 \mathrm{~cm}^{-1}$. It is important to note that both of these ranges overlap those given for the $\alpha$-helix (1645-166215,19 and $1238-1288^{11,15} \mathrm{~cm}^{-1}$, respectively) and the antiparallel-chain pleated sheet $\beta$ structure (1663-1674 13,14 and $1227-1240^{15,19} \mathrm{~cm}^{-1}$, respectively). In these assignments a question still remains as to whether the amide III band of the $\alpha$-helical structure is in fact strong enough to be observed. ${ }^{19}$

Underlying the above uncertainties is, of course, the consideration of whether unordered polypeptide chains should be expected to have vibrational frequencies as characteristic as those of regular structures, in view of the fact that the $\varphi, \psi$ angles of the latter occupy a much more limited region of conformational space than do (in principle) the $\varphi, \psi$ angles of the former. Furthermore, since particularly in globular proteins there is no a priori reason for the $\varphi, \psi$ distributions to be the same in all cases, it is entirely possible that unordered regions will have different average amide frequencies in different systems. Finally, we may ask whether the amide I and amide III regions are equally suited to the identification of unordered structures, given the observed distribution of frequencies for the $\alpha$-helical and $\beta$ structures.

In order to answer the kinds of questions raised above concerning the characteristics of the vibrational spectra of unordered polypeptide chains and their relation to the spectra of ordered structures, we have studied the Raman spectrum of the fibrous protein feather keratin. In its native state it is believed, from X-ray diffraction studies, to contain antiparallel-chain pleated sheet $\beta$ structure. ${ }^{23}$ This is consistent with infrared dichroic measurements. ${ }^{23}$ Infrared absorption analysis also indicates that this structure comprises about $28 \%$ of the protein, the remainder presumably being unordered. ${ }^{23}$ On the other hand, aqueous solutions of solubilized feather keratin are believed, from optical rotatory dispersion ${ }^{24}$ and circular dichroism ${ }^{25}$ studies, to be representative of essentially totally unordered polypeptide chains. This system thus lends itself naturally to a comparative Raman spectroscopic study. We have also combined such experimental work with normal vibration analyses in order to help elucidate some of the questions raised above.

\section{EXPERIMENTAL}

Duck (Anas platyrhynchos) quill was selected for study because it yielded much lower fluorescent background than sea gull (Larus novaehollandiae) quill. The calamus section was used, after being initially washed in warm soapy water and rinsed repeatedly in warm distilled water. The sample was air dried and then refluxed with petroleum ether $\left(30-40^{\circ} \mathrm{C}\right)$ 
for $24 \mathrm{hr}$ to remove waxes. Using $5145 \AA$ excitation, the native sample, cleaned in this manner, yielded very little fluorescent background. In order to avoid any possible heating effects, the strips of calamus $2 \mathrm{~mm}$ by $50 \mathrm{~mm}$ were enclosed in glass capillary tubes filled with $\mathrm{H}_{2} \mathrm{O}$ or $\mathrm{D}_{2} \mathrm{O}$. Front scattering and back scattering yielded similar signal to noise ratio. In all polarized scattering experiments the front scattering geometry was selected.

Several solubilized forms of feather keratin were prepared as described by Harrap and Woods ${ }^{26}$ and Bailey and Cole. ${ }^{27}$ After oxidation of the disulfide bonds with performic and peracetic acids, the extracted feather keratin was yellowish in color. Such a sample was not suitable for Raman work. Reduction by sodium sulfite and sodium tetrathionate generally yielded samples which were acceptable for Raman scattering. Sodium tetrathionate was prepared as described by Gilman. ${ }^{28}$ Generally a $80-90 \%$ solubilized feather keratin yield was obtained from the extraction. The remaining residue yielded no measurable Raman spectrum. The reformation of the $S-S$ bonds was prevented by reaction with iodoacetate at pH 9.5. No $509 \mathrm{~cm}^{-1}$ single bond $\mathrm{S}-\mathrm{S}$ stretching frequency was observed in the solubilized sample. Sodium sulfite was then added to destroy the excess iodoacetate, and the solution was dialyzed against $\mathrm{H}_{2} \mathrm{O}$ for 2 days at $4^{\circ} \mathrm{C}$. After the sample was concentrated with a size PM 10 Amicon filter, freeze drying yielded a clean white powder for further study.

A 6-10\% feather keratin solution was used to minimize the effect of gelation resulting from high concentration or heat. The elastic scattering caused by the local density fluctuations due to heating was reduced by using very small capillary tubes. In order to prepare the extracted feather keratin in solutions of $\mathrm{CH}_{3} \mathrm{OD}$ (Thomson and Packard Lot 1024, 99.0\% pure), it was important to add the $\mathrm{D}_{2} \mathrm{O}$ first, then the appropriate amount of $\mathrm{CH}_{3} \mathrm{OD}$. Although this yields very low sample concentration, generally only $3-5 \%$, the signal/noise ratio is acceptable.

Raman spectra were obtained on a spectrometer built in this laboratory and described elsewhere. ${ }^{29}$

\section{NORMAL VIBRATION ANALYSIS}

In order to evaluate the experimental results, and the sensitivity of the amide group frequencies to changes in geometry, we have carried out a normal vibrational analysis for $N$-acetyl-L-alanine- $N$-methylamide, $\mathrm{CH}_{3} \mathrm{CONHCH}\left(\mathrm{CH}_{3}\right) \mathrm{CONHCH}_{3}$. The geometries of this dipeptide model were varied from the potential minima associated with the $\alpha$-helical structure and the antiparallel-chain pleated $\beta$ sheet. The $\varphi$ and $\psi$ values were selected on the basis of conformational energies calculated for such a dipeptide. ${ }^{30}$ The force field was transferred from one refined for $\beta$ poly(L-alanine). ${ }^{5}$ Because of the effects of the end groups, the amide frequencies associated with the middle $\mathrm{C}^{\alpha}$ atom were selected since they are expected to be most representative of a polypeptide backbone. 
1516

HSU, MOORE, AND KRIMM

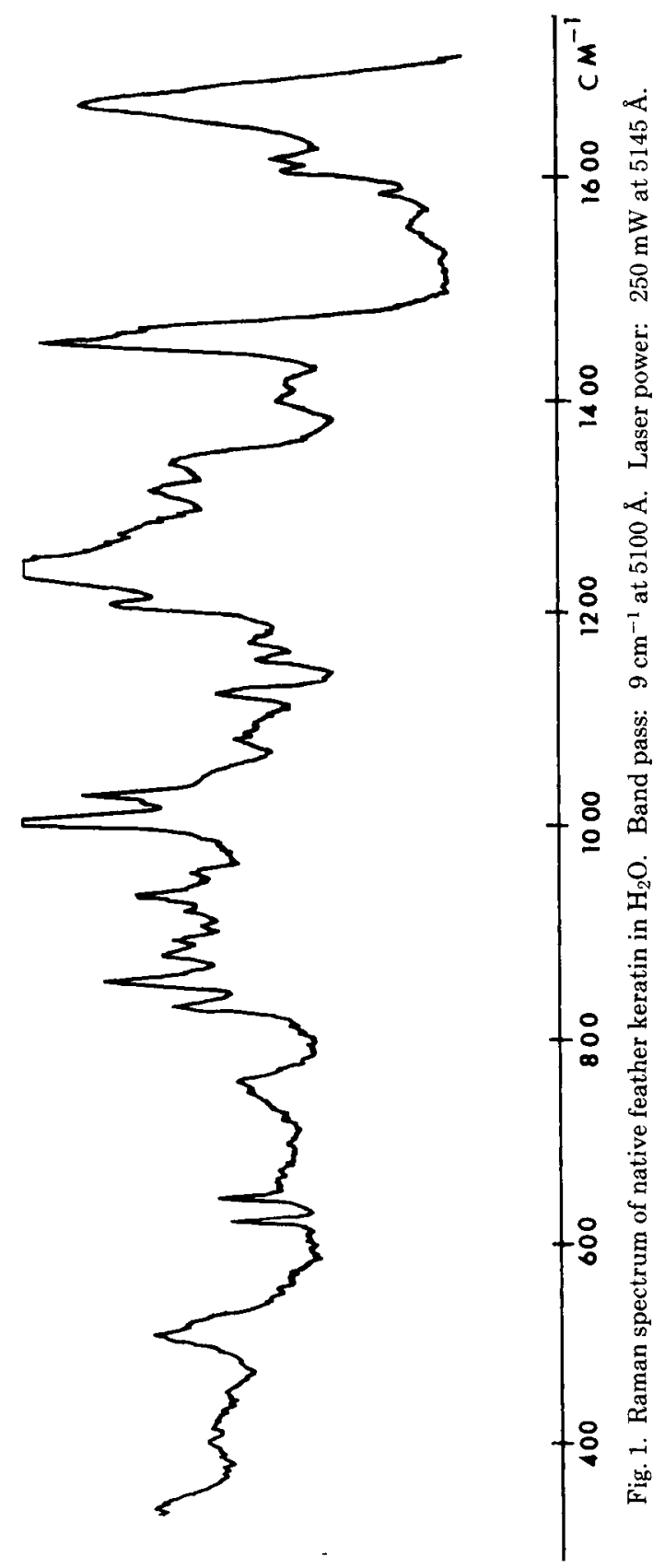



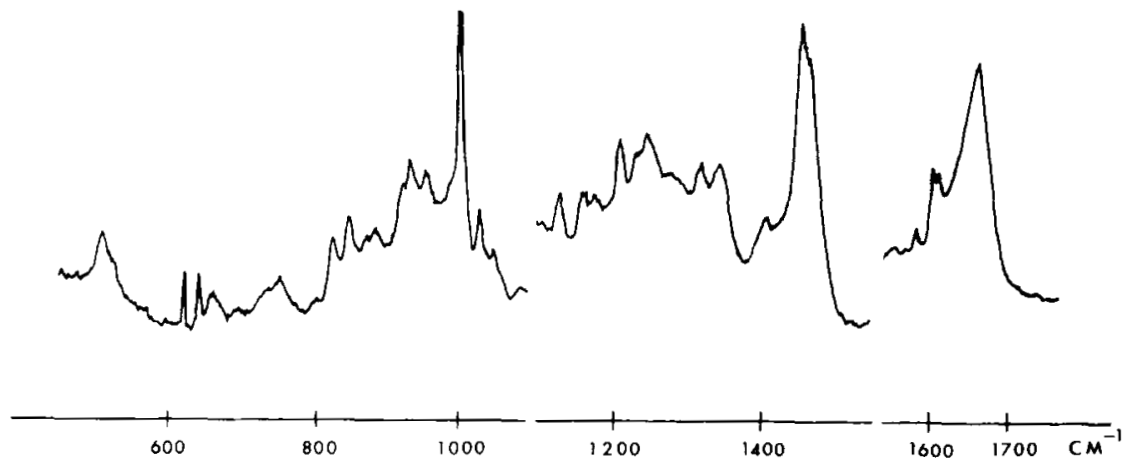

Fig. 2. Raman spectrum of native feather keratin in $\mathrm{D}_{2} \mathrm{O}$. Band pass: $7 \mathrm{~cm}^{-1}$ at $5100 \AA$. Laser power: $300 \mathrm{~mW}$ at $5145 \AA$.

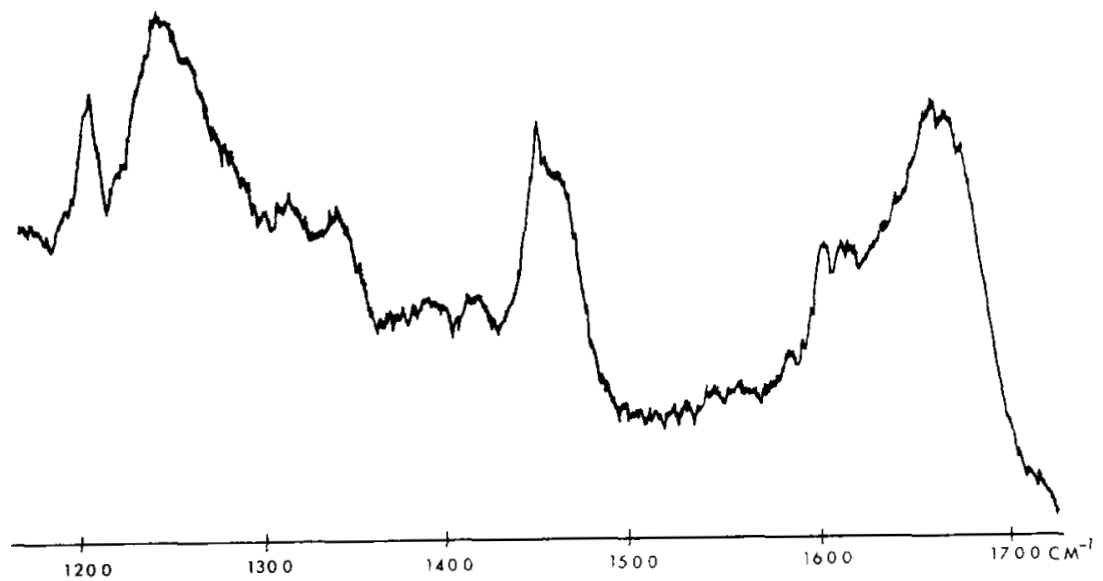

Fig. 3. Raman spectrum of solubilized feather keratin in $\mathrm{H}_{2} \mathrm{O}$. Band pass: $10 \mathrm{~cm}^{-1}$ at $5100 \AA$. Laser power: $150 \mathrm{~mW}$ at $5145 \AA$.

\section{RESULTS}

\section{Spectra}

The Raman spectra of native feather keratin immersed in $\mathrm{H}_{2} \mathrm{O}$ and $\mathrm{D}_{2} \mathrm{O}$ are presented in Figures 1 and 2, respectively. The amide I peak frequency occurs at $1671 \mathrm{~cm}^{-1}$ in the former and at $1668 \mathrm{~cm}^{-1}$ in the latter, typical of the $\sim 3 \mathrm{~cm}^{-1}$ decrease which occurs on deuteration of the peptide group. Spectra of solutions of feather keratin in $\mathrm{H}_{2} \mathrm{O}$ and $\mathrm{D}_{2} \mathrm{O}$ are given in Figures 3 and 4 , respectively. A similar shift in amide $I$ frequency is observed.

\section{Band Resolution}

In order to obtain a more quantitative measure of the contributions from the antiparallel-chain pleated sheet relative to the unordered protein, we 


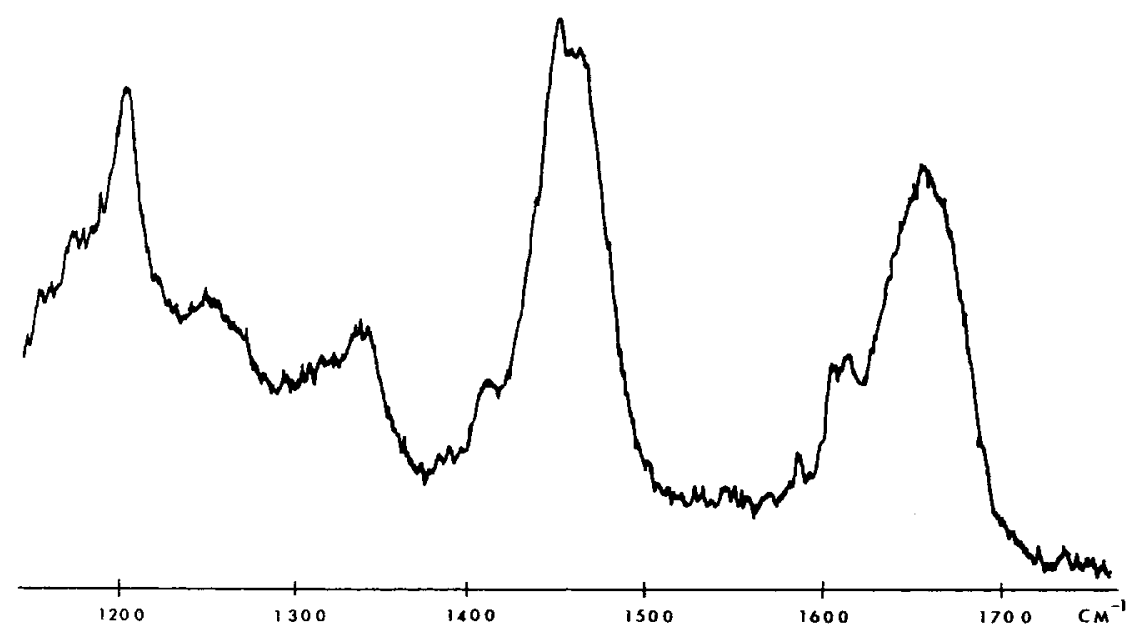

Fig. 4. Raman spectrum of solubilized feather keratin in $\mathrm{D}_{2} \mathrm{O}$. Band pass: $10 \mathrm{~cm}^{-1}$ at $5100 \AA$. Laser power: $150 \mathrm{~mW}$ at $5145 \AA$.

have used a band resolution technique to distinguish the overlapping bands involved. In general, an observed band can be approximated by a Gaussian function or a sum of Lorentzian and Gaussian functions. In the former case $f(x)=A f_{1}(x)$, whereas in the latter case $f(x)=A\left[g f_{1}(x)+(1-g) f_{2}(x)\right]$. In these equations: $f_{1}(x)=\exp \left[-(\ln 2)\left(2\left(x-x_{0}\right) / \Delta x\right)^{2}\right]$ and $f_{2}(x)=1 /[1$ $\left.+2\left(\left(x-x_{0}\right) / \Delta x\right)^{2}\right]$, where $x$ is the position along the abscissa, $x_{0}$ is the position of the peak, $\Delta x$ is the band width, $g$ is the relative contribution of the Gaussian component, and $A$ is the relative amplitude. In the band resolution, the computer programs were designed to accept three (height, position, and half width) or four (height, position, half width, and g) parameters for each peak depending on whether the Gaussian or a combination of Gaussian and Lorentzian functions was used. The least squares fitting was carried out using the observed data. No constraint was placed on the variation of parameters used. In general, 10-50 iterations (CPU time $\sim 20-300 \mathrm{sec}$ ) were carried out until the change in $\chi^{2}$ was reduced to less than $0.1 \%$ of the value calculated in the previous iteration. Convergence to a local minimum in $\chi^{2}$ space was avoided by a computer search of the region around the minimum.

In the amide I region we have subtracted the contributions from tryptophan, phenylalanine, and tyrosine side-chain bands, i.e., bands at 1556 $\mathrm{cm}^{-1}$ (Trp), $1584 \mathrm{~cm}^{-1}$ (Trp and Phe), $1605 \mathrm{~cm}^{-1}$ (Phe), and $1613 \mathrm{~cm}^{-1}$ (Trp, Tyr, Phe). The assignments of these bands are from the work of Lord and $\mathrm{Yu} .{ }^{10}$ Because of their sharpness, we have elected not to resolve the 1605 and $1613 \mathrm{~cm}^{-1}$ bands during fitting. Biochemical analysis and infrared spectroscopy of feather keratin show that the side chain amide groups and some amino-acid residues may make contributions in the amide I region. However, from amino-acid concentration studies Fraser concluded that only glutamine and asparagine are likely to contribute significantly. ${ }^{23}$ To determine the amount of their contributions, Raman spectra 


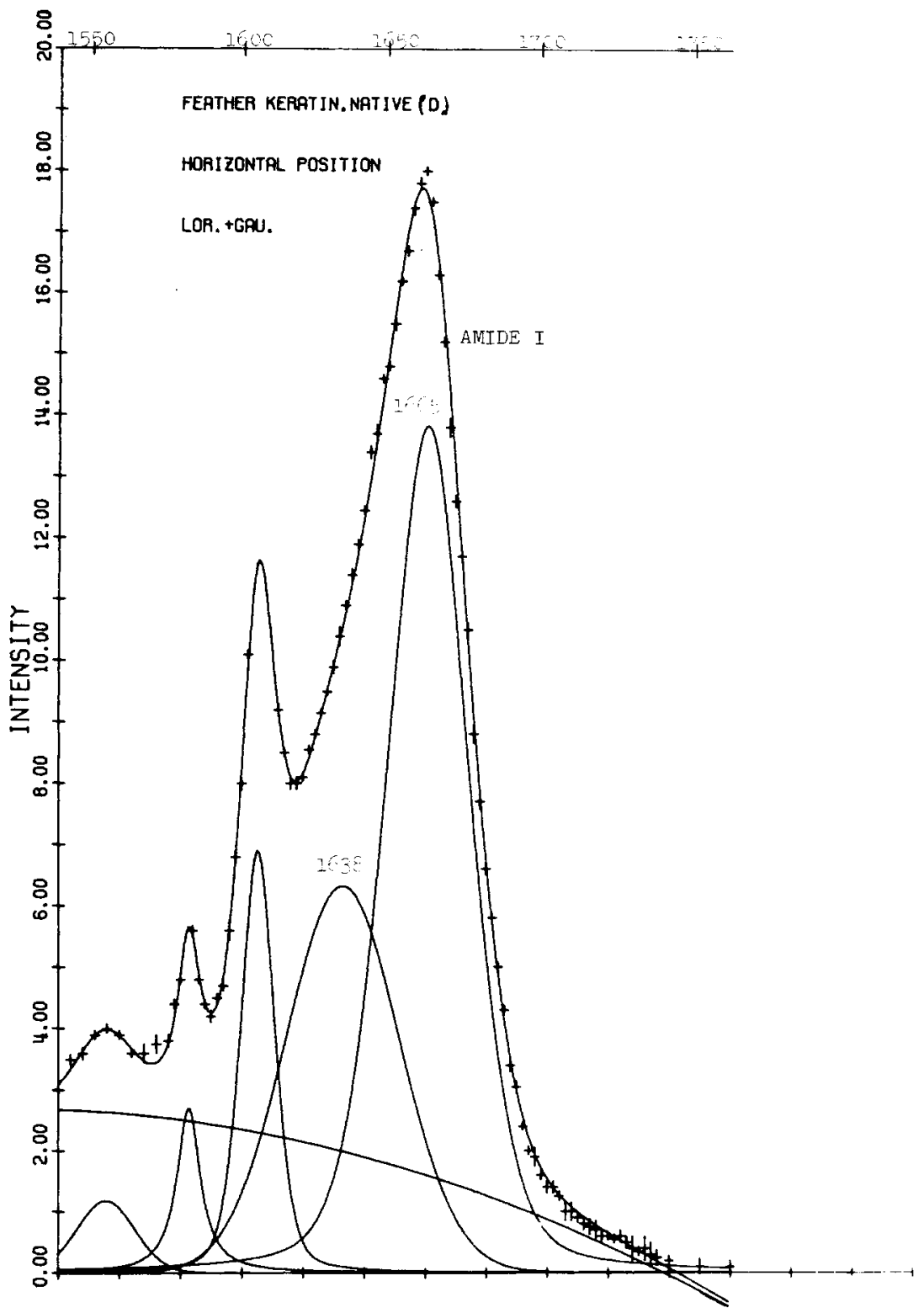

Fig. 5. The resolved components of the amide I band in native feather keratin.

of propionamide (Aldrich, Batch 071037), N-methylacetamide (Eastman Kodak), and a 50-50 mixture of the two were obtained. $N$-methylacetamide has a strong amide I band at $1648 \mathrm{~cm}^{-1}$. Propionamide has a strong band at $1671 \mathrm{~cm}^{-1}$. Raman spectra of the $1: 1$ mixture showed that the 1671 $\mathrm{cm}^{-1}$ band is considerably weaker than the $1648 \mathrm{~cm}^{-1}$ component. Given their relatively small percentage contributions, ${ }^{23}$ the error caused by neglecting $\mathrm{CONH}_{2}$ groups can be ignored. 


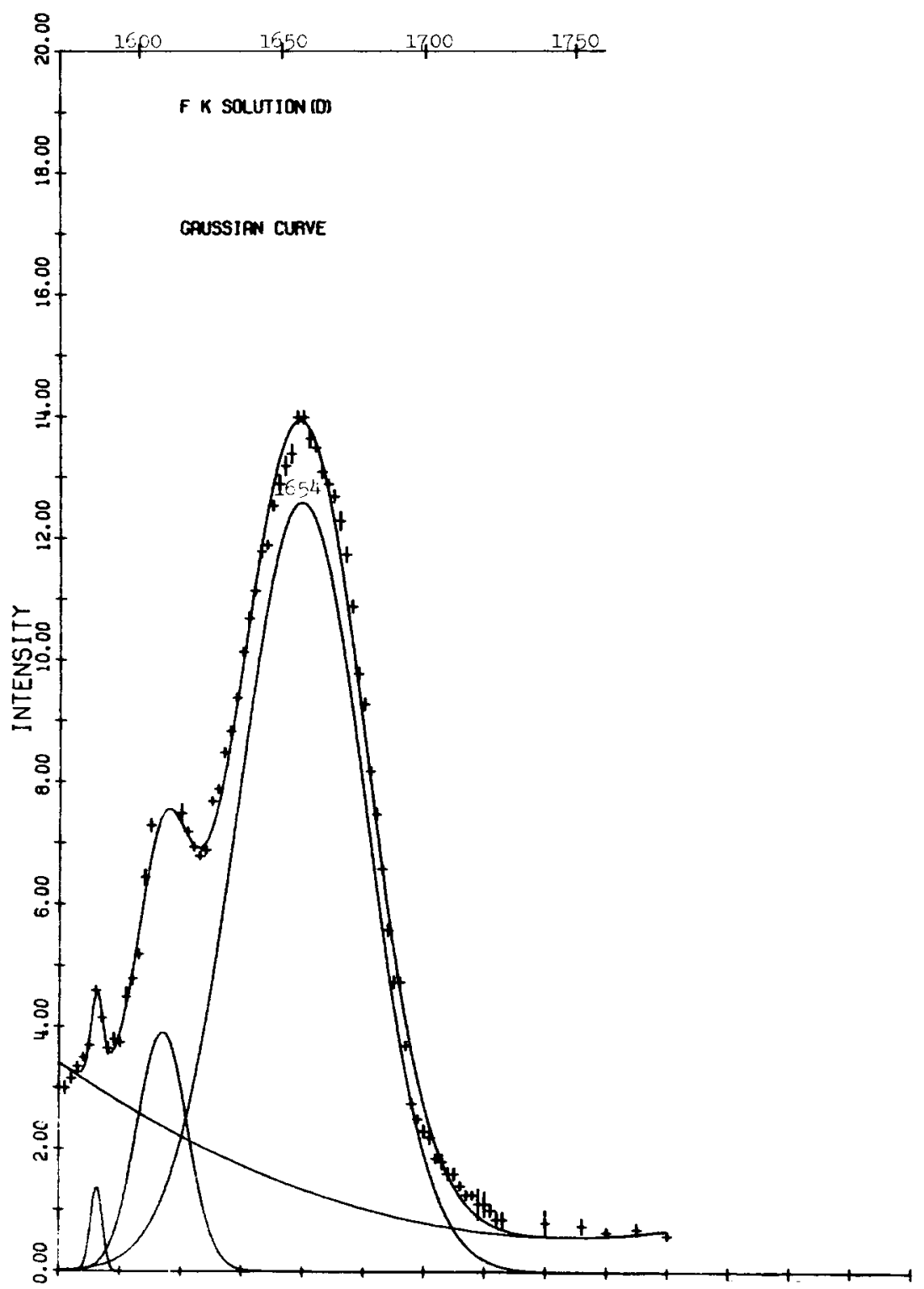

Fig. 6. The resolved components of the amide I band in solubilized feather keratin solution $\left(\mathrm{D}_{2} \mathrm{O}\right)$.

The result of the fit for native feather keratin in $\mathrm{D}_{2} \mathrm{O}$, which requires Lorentzian plus Gaussian functions, is shown in Figure 5. The asymmetric amide I region is resolved into a sharp band at $1665 \mathrm{~cm}^{-1}$ and a considerably wider band near $1640 \mathrm{~cm}^{-1}$. A similar procedure was used to analyze the solubilized feather keratin in $\mathrm{D}_{2} \mathrm{O}$ solution. Unlike the fit for the native state, where the gaussian function described the data very poorly, the amide I band in the unordered state could be described very well with a single wide 
Gaussian function. The results of this fit are shown in Figure 6. The data on these least squares fits are given in Table I.

The strong broad band observed at $1235 \mathrm{~cm}^{-1}$ in $\mathrm{H}_{2} \mathrm{O}$ for native feather keratin can be assigned to the amide III mode. This band moves to the $900-1000 \mathrm{~cm}^{-1}$ region after deuteration, as expected. The corresponding band is at $1246 \mathrm{~cm}^{-1}$ in feather keratin solution (in $\mathrm{H}_{2} \mathrm{O}$ ). Bands at 1206 , 1226,1246 , and $1276 \mathrm{~cm}^{-1}$ remain after the sample is immersed in $\mathrm{D}_{2} \mathrm{O}$ for $48 \mathrm{hr}$. Since $\mathrm{H} \rightarrow \mathrm{D}$ exchange can take place very quickly in the $\beta$ confor mation, ${ }^{31}$ and the above treatment is likely to have exchanged all the hydrogens associated with peptide groups for deuterium whether hydrogen bonded or not, ${ }^{32}$ we have assigned the four bands listed above to contributions from amino-acid side chains.

When feather keratin is solubilized, only cystine and tryptophan react with iodoacetate and sulfite. ${ }^{26}$ From amino acid $^{33}$ and Raman scattering ${ }^{11}$ studies, the contribution from tryptophan is expected to be small in this region. Since no other amino acids are affected during the extraction process, we have used the $1206 \mathrm{~cm}^{-1}$ (possibly tyrosine) band, which is resolved from the main amide III band, as a reference to subtract it and the 1226,1246 , and $1276 \mathrm{~cm}^{-1}$ bands from the composite band in the amide III region of undeuterated samples.

When such a subtraction is performed for native feather keratin, the result of a minimum $\chi^{2}$ fit (shown in Figure 7 ) is an intense band of Gaussian shape and $30 \mathrm{~cm}^{-1}$ half width located at $1233 \mathrm{~cm}^{-1}$. No unique separation of this band into two components was possible. When the subtraction was done on the spectrum of the solubilized feather keratin, it was not possible to fit the remaining band with any single function and obtain a minimum in $\chi^{2}$. Nor was the situation improved if two functions were used. The amide III scattering in this case is obviously a complex resultant of many component contributions.

\section{Normal Vibration Analysis}

The calculated amide I frequencies for selected values of $\varphi$ and $\psi$ are shown in Figure 8, superimposed on a conformational energy map of a dipeptide. ${ }^{30}$ Calculated amide III frequencies for the same $\varphi$ and $\psi$ values are shown in Figure 9.

TABLE I

Band Resolution of the Amide I Region $\left(\mathrm{D}_{2} \mathrm{O}\right)$

\begin{tabular}{|c|c|c|c|}
\hline \multirow[b]{2}{*}{ Sample function } & \multicolumn{2}{|c|}{ Native } & \multirow[b]{2}{*}{ Solubilized, : } \\
\hline & $1+g$ & $\mathrm{~g}$ & \\
\hline Position, $\mathrm{cm}^{-1}$ & 1665 & 1638 & $1654 \mathrm{~cm}^{-1}$ \\
\hline $1 / 2$ width, $\mathrm{cm}^{-1}$ & 31 & 46.5 & $52 \mathrm{~cm}^{-1}$ \\
\hline Area, $\%$ & 64 & 36 & 100 \\
\hline$\chi^{2}$ red. & \multicolumn{2}{|c|}{4.6} & 4.3 \\
\hline
\end{tabular}




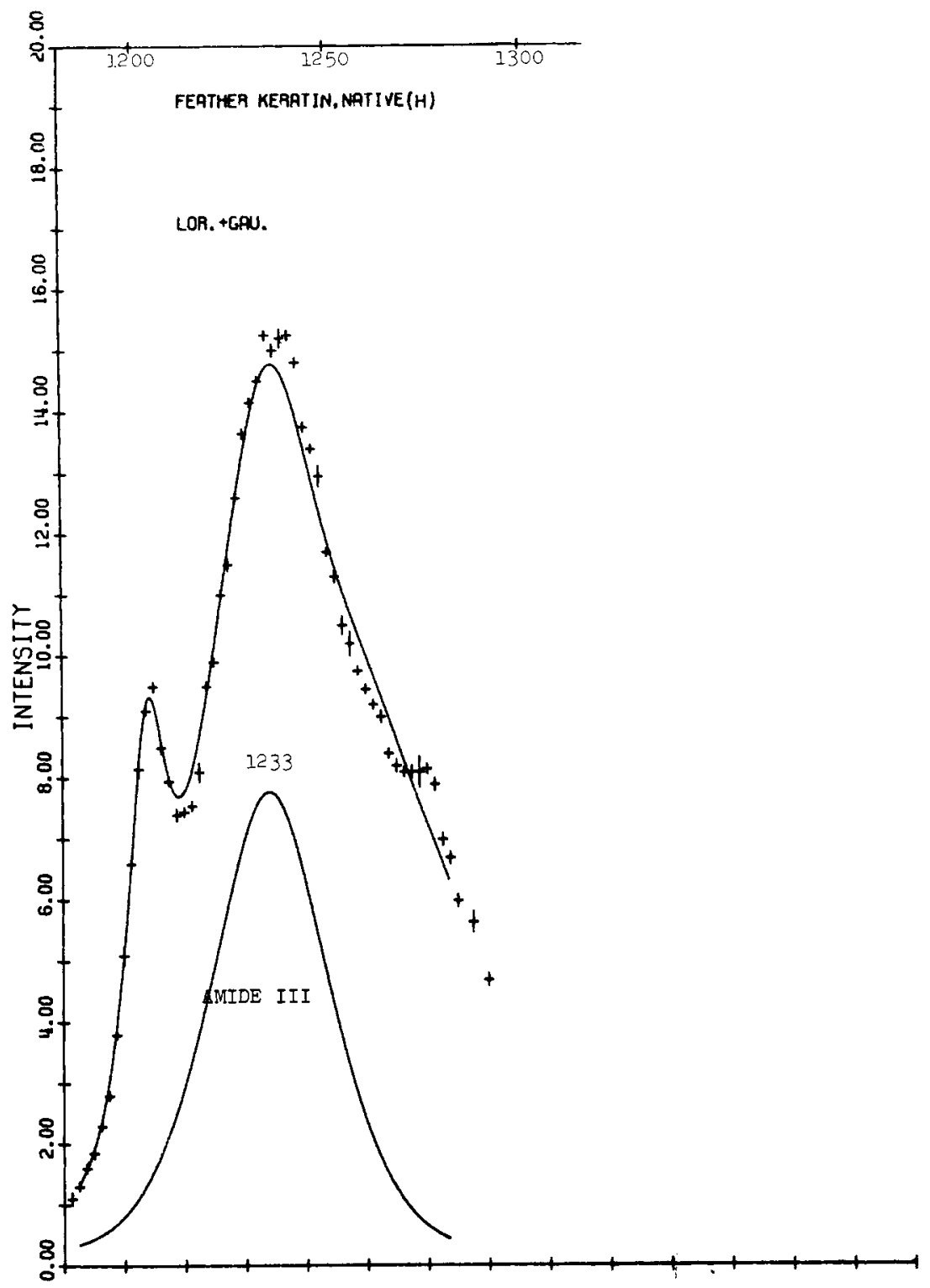

Fig. 7. The resolved amide III band in native feather keratin.

\section{DISCUSSION}

Early X-ray studies ${ }^{34}$ suggested the presence of a $\beta$ structure in native feather keratin, and infrared dichroic studies ${ }^{35}$ were consistent with this proposal. Recent X-ray and infrared studies ${ }^{23}$ indicate that the $\beta$ structure is an antiparallel-chain pleated sheet. Our Raman studies, which show a strong band near $1670 \mathrm{~cm}^{-1}$ in the native state (in $\mathrm{H}_{2} \mathrm{O}$ ), support this proposal, since the parallel-chain pleated sheet structure is expected to have a lower characteristic frequency..$^{3,4}$ 


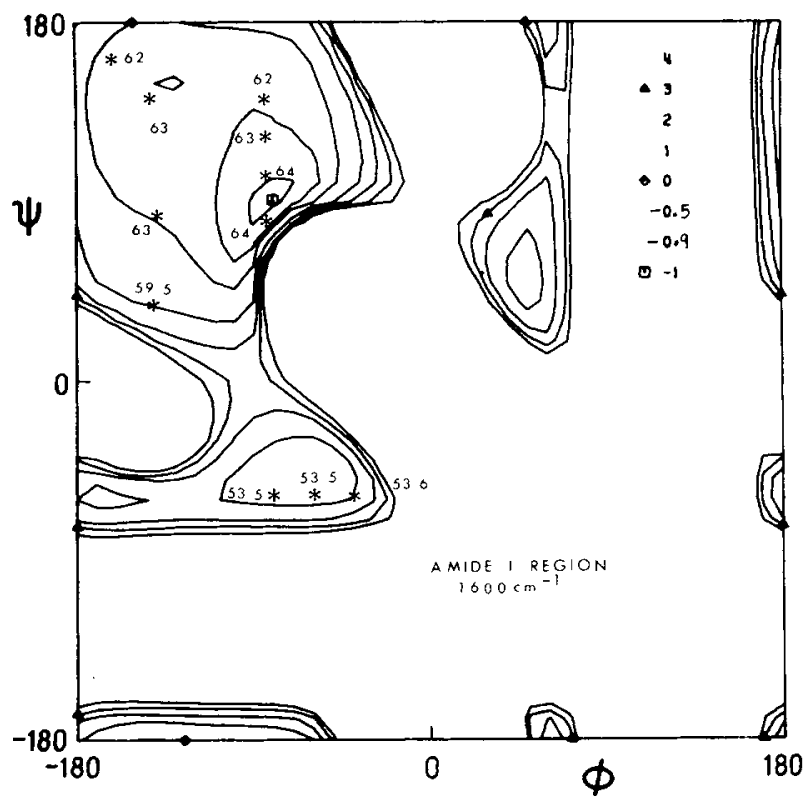

Fig. 8. Variation of amide I frequencies as a function of $\varphi$ and $\psi$ in $N$-acetyl-L-alanine$N$-methylamide.

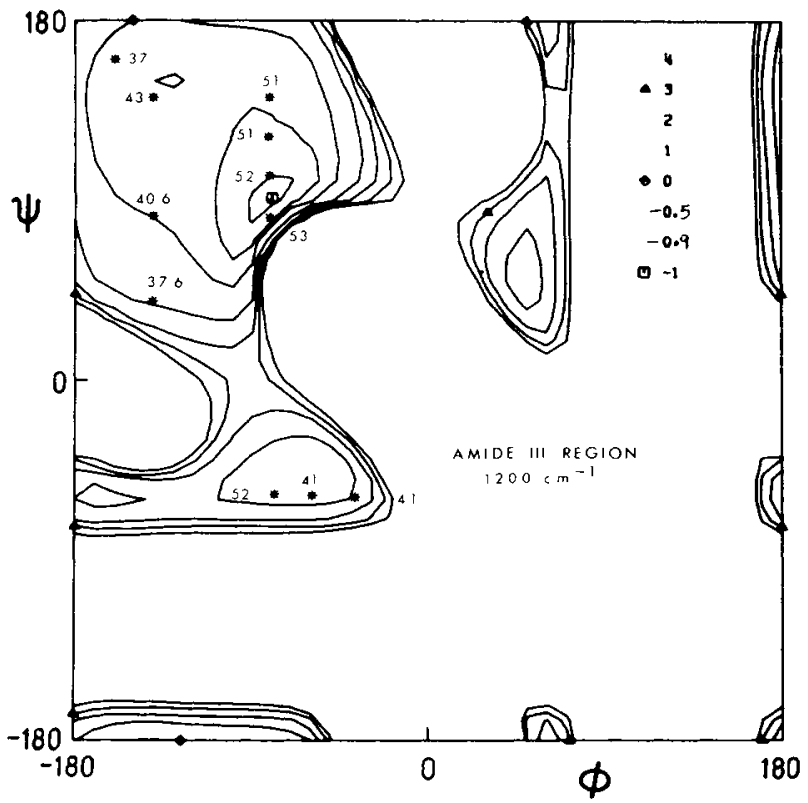

Fig. 9. Variation of amide III frequencies as a function of $\varphi$ and $\psi$ in $N$-acetyl-L-alanine$N$-methylamide.

The above infrared analysis ${ }^{23}$ suggests that only $28 \%$ of the protein consists of an ordered $\beta$ structure, the remaining portion being devoid of any secondary structure. Our band resolution of the amide I region (Fig. 5 and Table I) also leads to the conclusion that two components are present, 
an ordered $\beta$ structure represented by the relatively sharp high frequency band and an unordered component represented by the broader lower frequency band. These assignments are consistent with the correlations discussed in the Introduction. The band areas which we obtain from this resolution, however, suggest a significantly higher proportion of ordered component. From Figure 5 we find that the area associated with the $\beta$ component comprises $64 \%$ of the total amide I scattering. This probably represents a minimum value of the $\%$ of $\beta$ structure (assuming that the scattering efficiencies of $\beta$ and unordered structures are the same), since in this spectrum the electric vector of the incident radiation, $E_{0}$, is perpendicular to the $\mathrm{C}=\mathrm{O}$ bond. We believe that the infrared values may reflect what we now know ${ }^{3,4}$ to be an incorrect assignment ${ }^{23}$ of component bands in the amide I region.

Our assignments for these two component bands are also supported by the observation of the expected polarization effects for the amide I mode..$^{9,36}$ Snyder has demonstrated that the induced polarizability change along a bond may be quite different from that perpendicular to the bond. ${ }^{37,38}$ There should, therefore, be relatively different scattered light intensities with the electric vector, $E_{0}$, oriented parallel and perpendicular to the $\mathrm{C}=\mathrm{O}$ bond of the $\beta$ sheet. On the other hand, for the unordered component the intensities should be comparable for the two polarization directions. This is indeed found to be the case, as is shown in Figure 10. Using the 1605, $1613 \mathrm{~cm}^{-1}$ bands as an internal standard, we see that there is a much larger contribution in the $1670 \mathrm{~cm}^{-1}$ region when $E_{0}$ is parallel to the $\mathrm{C}=0$ bond (i.e., perpendicular to the quill axis) than when $E_{0}$ is perpendicular to this bond, but that the scattering in the $1640 \mathrm{~cm}^{-1}$ region is approximately the same for both polarizations. From the geometries used, depolarization of the incident beam cannot alter this result. ${ }^{37,38}$

Soluble feather keratin has been shown from circular dichroism studies ${ }^{25}$ to consist of completely unordered polypeptide chains. Although this conclusion was based on what was then a suggested revision of the assignment of the circular dichroism spectrum, subsequent theoretical ${ }^{39,40}$ and experimental ${ }^{41}$ studies have firmly established the validity of this new assignment. The above structural characterization of soluble feather keratin thus has a firm independent base. The observed amide I region Raman spectrum of this material (Figure 6 and Table I) consists of a broad ( $\sim 50$ $\mathrm{cm}^{-1}$ half width) Gaussian band centered at a value $\left(1654 \mathrm{~cm}^{-1}\right.$ in $\mathrm{D}_{2} \mathrm{O}$ solution, expected about $3 \mathrm{~cm}^{-1}$ higher in $\mathrm{H}_{2} \mathrm{O}$ ) consistent with those expected of disordered structures. The breadth of this band is such that it easily overlaps the frequency range associated with $\alpha$-helical as well as $\beta$ conformations. It is interesting that the half width of this band is comparable to that of the band in native feather keratin that was assigned to unordered structures, although the former is about $16 \mathrm{~cm}^{-1}$ higher in frequency than the latter.

It is clear that the greater width of the band assigned to the unordered component must be due to the larger range in $\varphi$ and $\psi$ encompassed by such 

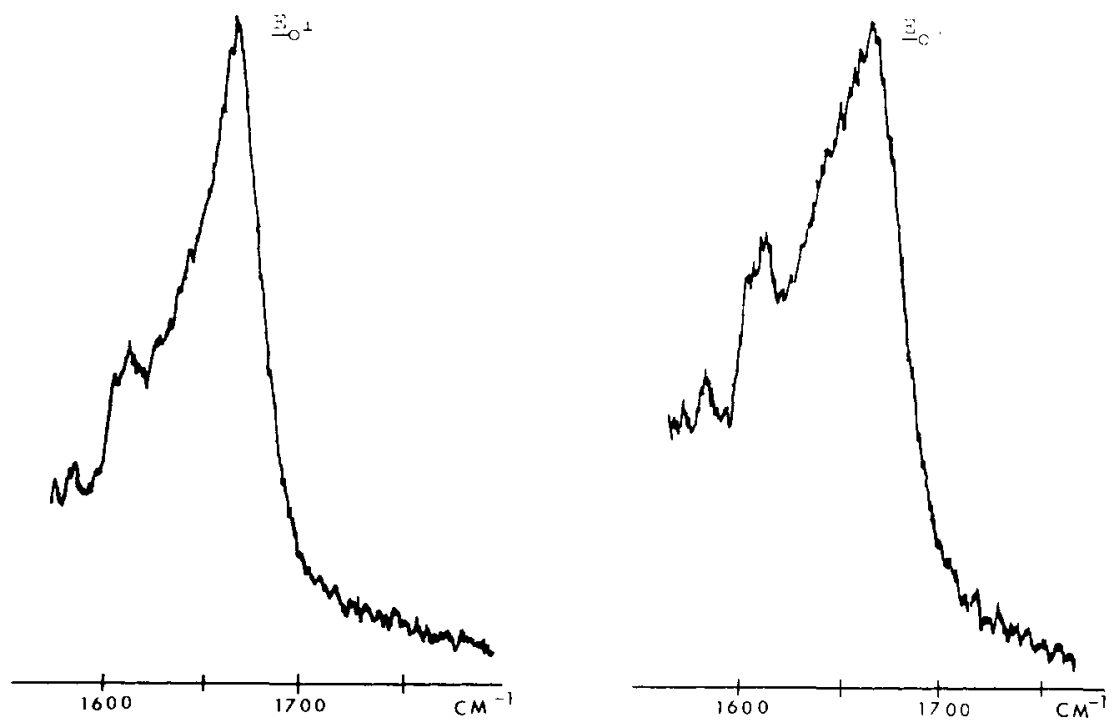

Fig. 10. Amide I band observed in native feather keratin with $E_{0}$ perpendicular and parallel to the quill axis.

a distribution. This is illustrated by the results of the normal vibration calculation for the amide I mode (Fig. 8). The frequency distribution for $\alpha$-helical conformations is very narrow, and that for extended conformations is only about $2 \mathrm{~cm}^{-1}$, but the difference between these two regions is $10.5 \mathrm{~cm}^{-1}$. Thus, a (supposedly) narrow frequency range $\left(1-2 \mathrm{~cm}^{-1}\right)$ associated with a regular $\beta$ conformation would be broadened to about 12 $\mathrm{cm}^{-1}$ in an unordered distribution containing both $\alpha$ and $\beta$ conformations. Of course, since hydrogen bonding and interaction effects ${ }^{3,4}$ have been neglected in this calculation, it cannot be expected to reproduce either the inherent breadth of a band associated with a regular structure or probably even the exact numerical shift between the two kinds of conformations. If, however, a "natural" width for an ordered $\beta$ structure is about $30 \mathrm{~cm}^{-1}$ (cf. Table I), it is perhaps not surprising, in view of the calculations, that the width associated with the unordered distribution should be about $50 \mathrm{~cm}^{-1}$.

If we accept the above analysis, it is obvious that the average frequency observed for an unordered distribution of $\varphi$ and $\psi$ in an ensemble of polypeptide chains will depend on the exact form of the distribution. The average over a dipeptide energy map (such as the one in Figure 8) corresponding to an in vacuo calculation will be different from that over a solvent-perturbed map, ${ }^{30,42}$ and different from the average over the actual conformational distribution, which may involve specific local (primary structure) as well as long-range interactions. It should, therefore, not be surprising that the frequency found for the unordered component of the native protein $\left(1638 \mathrm{~cm}^{-1}\right)$ is different from that observed for the solubilized protein $\left(1654 \mathrm{~cm}^{-1}\right)$, nor that the band widths are slightly different. In- 

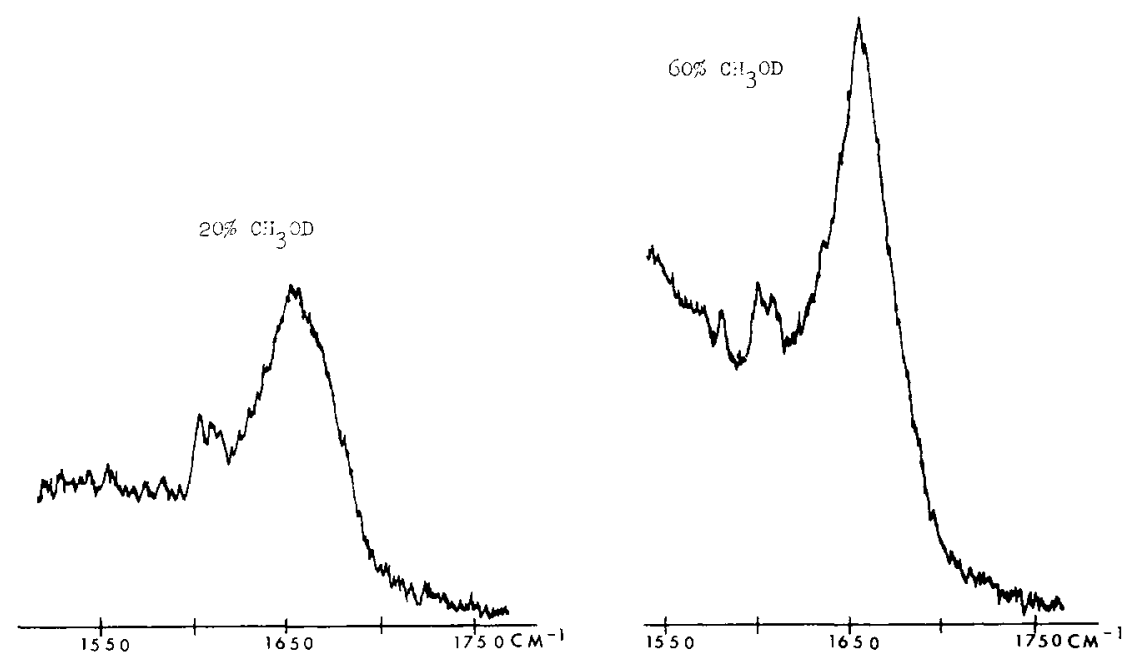

Fig. 11. Raman spectrum of solubilized feather keratin in $\mathrm{CH}_{3} \mathrm{OD}$ solution.

cidentally, if we accept the general trends given by the normal vibration calculations, then we would infer that the unordered component of the protein contains a higher proportion of $\alpha$-helical conformations than does the solubilized feather keratin.

Another consequence of our analysis is that it may be possible for the band width associated with an unordered distribution to change without a significant change occurring in its average frequency. Solubilized feather keratin provides an illustration of this behavior. It is $\mathrm{known}^{25}$ that the addition of $\mathrm{CH}_{3} \mathrm{OH}$ to an aqueous solution of feather keratin changes the circular dichroism spectrum in a manner indicating that $\beta$ type conformations are favored. In Figure 11 we show the effect of increasing concentrations of $\mathrm{CH}_{3} \mathrm{OD}$ on the Raman spectrum of solubilized feather keratin. The position of the amide I peak is essentially unaltered from its value in aqueous solution $\left(1657 \mathrm{~cm}^{-1}\right.$ in $\left.\mathrm{D}_{2} \mathrm{O}\right)$, but the half width has decreased from $52 \mathrm{~cm}^{-1}$ to $40 \mathrm{~cm}^{-1}$ in $20 \% \mathrm{CH}_{3} \mathrm{OD}$ and to $30 \mathrm{~cm}^{-1}$ in $60 \% \mathrm{CH}_{3} \mathrm{OD}$. This indicates that the conformational distribution narrows in $\mathrm{CH}_{3} \mathrm{OH}$. If $\beta$ type conformations are indeed favored, ${ }^{25}$ these results indicate that, since the peak does not shift to $1665 \mathrm{~cm}^{-1}$ (the frequency associated with a sheet structure), these conformations occur in single chain structures and not in a "condensed" hydrogen-bonded sheet.

We turn our attention now to the amide III region. The observed $1235-1239 \mathrm{~cm}^{-1}$ band in native feather keratin (in $\mathrm{H}_{2} \mathrm{O}$ ) is observed to shift to $1246 \mathrm{~cm}^{-1}$ in the solubilized form, consistent with a $\beta$ to unordered conversion. Using the $1206 \mathrm{~cm}^{-1}$ band as a reference, there is only a slight increase in overall band width in solution, and about a $20 \%$ reduction in intensity. Since the reaction of cystine and tryptophan with sulfite and iodoacetate cannot account for the reduction in intensity, we associate the shift in frequency, the increase in band width, and the decrease in intensity with the transformation from a partially ordered to an unordered structure. 
The normal vibration calculations (Fig. 9) again help us understand the nature of the changes taking place. Unlike the amide I region, the frequencies calculated for the amide III band are very sensitive to small changes in $\varphi$ and $\psi$. In the $\alpha$-helical region a change of $10^{\circ}$ in $\varphi$ causes a shift of $11 \mathrm{~cm}^{-1}$. In the $\beta$ region a similar trend exists, with a change of $6 \mathrm{~cm}^{-1}$ for a $10^{\circ}$ variation of $\varphi$ and $\psi$. Over the entire region of $\varphi=0$ to $\varphi=-160^{\circ}$ and $\psi=0$ to $\psi=160^{\circ}$, there is a shift of $16 \mathrm{~cm}^{-1}$. This result clearly indicates that the amide III band is very sensitive to the conformation of the polypeptide chain. Even a small deviation from a well-defined structure causes the observed band to encompass a distribution of frequencies. This is what we observe in feather keratin where both native and solubilized forms have about the same band width. Furthermore, our inability to describe the amide III band contour of soluble feather keratin with one single function also indicates the presence of a wide range of polypeptide chain conformations.

\section{CONCLUSIONS}

The combined Raman studies of native and solubilized feather keratin lead to several conclusions about this fibrous protein. The spectra of the native form are consistent with a protein containing $64 \%$ of antiparallelchain pleated sheet structure and $36 \%$ of an unordered component. In the solubilized form the protein is $100 \%$ unordered, although its conformational distribution differs from the unordered component of the native state.

Our studies help to clarify the nature of the vibrational spectra to be associated with unordered polypeptide chains. In the first place, there can be no limited amide I frequency region which characterizes all unordered systems, since the average frequency will depend on the conformational distribution present. This point has already been made on the basis of circular dichroism studies. ${ }^{41}$ Second, keeping the above point in mind, it nevertheless seems to be the case that the broadest conformational distribution gives rise to a broad band in the $1654-1660 \mathrm{~cm}^{-1}$ region. The results on silk $^{8}$ and our feather keratin studies support this conclusion. This does not, of course, rule out the possibility that the range should be broadened to the $1649-1667 \mathrm{~cm}^{-1}$ value noted in the Introduction. Third, and probably most important, although the amide I band can be used to identify unordered structures within the conditions stated above, it seems to us that the amide III band cannot be used in this way. Its much greater sensitivity to the details of the conformational distribution implies that small variations in secondary structure will lead to significant shifts in frequency. We do not believe that the amide III band position should therefore be used to characterize unordered polypeptide chain structures.

This research was supported by National Science Foundation grants BMS74-21163 and MPS75-05239, and by a Macromolecular Research Center fellowship to S.L.H. The authors 
wish to thank Dr. M. Lois Tiffany for providing the feather keratin and helping with the oxidation of some of the samples. They are deeply grateful to Professor G. W. Jourdian for making his laboratory facilities available.

\section{References}

1. Bamford, C. H., Elliott, A. \& Hanby, W. E. (1956) Synthetic Polypeptides, Academic Press, New York.

2. Miyazawa, T. (1967) Poly- $\alpha$-Amino Acids, G. D. Fasman, Ed., Dekker, New York, pp. 69-103.

3. Krimm, S. \& Abe, Y. (1972) Proc. Natl. Acad. Sci. (U.S.) 69, 2788-2792.

4. Moore, W. H. \& Krimm, S. (1975) Proc. Natl. Acad. Sci. (U.S.) 72, 4933-4935.

5. Moore, W. H. \& Krimm, S. (1976) Biopolymers, to be published.

6. Miyazawa, T. \& Blout, E. R. (1961) J. Amer. Chem. Soc. 83, 712-719.

7. Krimm, S. (1962) J. Mol. Biol. 4, 528-540.

8. Suzuki, E. (1967) Spectrochim. Acta 23A, 2303-2308.

9. Fanconi, B., Tomlinson, B., Nafie, L. A., Small, W. \& Peticolas, W. L. (1969) J. Chem. Phys. 51, 3993-4005.

10. Lord, R. C. \& Yu, N. T. (1970) J. Mol. Biol. 50, 509-524; 51, 203-213.

11. Koenig, J. L. \& Frushour, B. (1972) Biopolymers 11, 1871-1892.

12. Wallach, D. F. H., Graham, J. M. \& Oseroff, A. R. (1970) FEBS Letters 7, 330-334.

13. Sutton, P. \& Koenig, J. L. (1970) Biopolymers 9, 615-634.

14. Small, E. W., Fanconi, B. \& Peticolas, W. L. (1970) J. Chem. Phys. 52, 4369-4379.

15. Yu, N. T., Liu, C. S. \& O'Shea, D. C. (1972) J. Mol. Biol. 70, 117-132.

16. Yu, N. T., Jo, B. H. \& Liu, C. S. (1972) J. Amer. Chem. Soc. 94, 7572-7575.

17. Koenig, J. L. (1972) J. Polym. Sci.-Pt. D, 6, 59-177.

18. Yu, N. T. \& Jo, B. H. (1973) J. Amer. Chem. Soc. 95, 5033-5037.

19. Yu, T. J., Lippert, J. L. \& Peticolas, W. L. (1973) Biopolymers 12, 2161-2176.

20. Chen, M. C., Lord, R. C. \& Mendelsohn, R. (1974) J. Amer. Chem. Soc. 96, 3038-3042.

21. Chen, M. C. \& Lord, R. C. (1974) J. Amer. Chem. Soc. 96, 4750-4752.

22. Frushour, B. G. \& Koenig, J. L. (1975) Biopolymers 14, 379-391.

23. Fraser, R. D. G., MacRae, T. P., Parry, D. A. D. \& Suzuki, E. (1971) Polymer 12, 35-56.

24. Westover, C. J., Tiffany, M. L. \& Krimm, S. (1962) J. Mol. Biol. 4, 316-318.

25. Tiffany, M. L. \& Krimm, S. (1969) Biopolymers 8, 347-359.

26. Harrap, B. S. \& Woods, E. F. (1964) Biochem. J. 92, 8-18.

27. Bailey, J. L. \& Cole, R. D. (1959) J. Biol. Chem. 234, 1733-1739.

28. Gilman, A., Philips, F. S., Koelle, E. S., Allen, R. P. \& St. John, E. (1946) Amer. J. Physiol. 147, 115-126.

29. Hsu, S. L., Moore, W. H. \& Krimm, S. (1975) J. Appl. Phys. 46, 4185-4193.

30. Venkatachalam, C. M. \& Krimm, S. (1973) Conformation of Biological Molecules and Polymers, Israel Academy of Sciences and Humanities, Jerusalem, pp. 141-154.

31. Lenormant, H., Baudras, A. \& Blout, E. R. (1958) J. Amer. Chem. Soc. 80, 6191-6195.

32. Nakanishi, M. \& Tsuboi, M. (1974) J. Mol. Biol. 83, 379-391.

33. Harrap, B. S. \& Woods, E. F. (1967) Comp. Biochem. Physiol. 20, 449-460.

34. Astbury, W. T. \& Marwick, T. C. (1932) Nature 130, 309-310.

35. Ambrose, E. J. \& Elliott, A. (1951) Proc. Royal Soc. (London) A206, 206-219.

36. Wilser, W. T. \& Fitchen, D. B. (1975) J. Chem. Phys. 62, 720-724.

37. Snyder, R. G. (1971) J. Mol. Spectroscopy 36, 222-231.

38. Snyder, R. G. (1971) J. Mol. Spectroscopy 37, 353-365.

39. Ronish, E. W. \& Krimm, S. (1972) Biopolymers 11, 1919-1928.

40. Ronish, E. W. \& Krimm, S. (1974) Biopolymers 13, 1635-1651.

41. Krimm, S. \& Tiffany, M. L. (1974) Israel J. Chem. 12, 189-200.

42. Krimm, S. \& Venkatachalam, C. M. (1971) Proc. Natl. Acad. Sci. (U.S.) 68, 2468-2471.

Received November 10, 1975

Accepted January 21, 1976 